\title{
O perfil do profissional contábil a partir da visão de professores e alunos de uma instituição de ensino superior
}

\section{The profile of professional accounting from the teacher vision and students of a higher education institution}

\author{
Paulo Henrique Leal \\ Universidade federal do sul e sudeste do Pará - UNIFESSPA \\ pa.henriqueleal@gmail.com
}

Mestre em Administração e Controladoria pelo Programa de Pós-Graduação em Administração e Controladoria da Universidade Estadual do Ceará - UFC

Professor do curso de Ciências Contábeis, Instituto de Ciências Sociais Aplicadas da

Universidade Federal do Sul e Sudeste do Pará - ICSA/UNIFESSPA

Benedito Manoel do Nascimento Costa
UNIVERSIDADE DO ESTADO DO RIO GRANDE DO NORTE - UERN
beneditocosta50@gmail.com

Mestre em Administração e Controladoria pelo Programa de Pós-Graduação em Administração e Controladoria da Universidade Estadual do Ceará - UFC

Professor do Departamento de Ciências Contábeis da Universidade do Estado do Rio Grande do Norte - UERN

\section{Bruno Figueiredo dos Santos}

Faculdade de Juazeiro do Norte - FJN

b.figueiredo16@gmail.com

Graduando em Ciências Contábeis pela Faculdade de Juazeiro do Norte - FJN

\begin{abstract}
RESUMO
O presente estudo buscou responder o seguinte questionamento: qual a visão dos professores e estudantes do curso de Ciências Contábeis de uma instituição de ensino superior privada em relação ao profissional da contabilidade? Para isso, o objetivo do trabalho foi analisar a visão dos professores e estudantes do curso de Ciências Contábeis de uma instituição de ensino superior privada em relação ao profissional da contabilidade. A metodologia utilizada para a realização desse trabalho foram aplicados questionários a dois grupos, um de docentes e o outro de discentes. Os resultados apontam que a maioria dos professores pesquisados possui título de especialista ou de mestre, com formação em contabilidade e que buscam formação complementar. Em relação aos discentes pesquisados, constatou-se que a maioria atua na área contábil e desejam atuar como empresários de contabilidade.
\end{abstract}

Palavras-chave: profissional contábil, percepção, professores e alunos.

\section{ABSTRACT}

This Study sought to answer the following question: what is the vision of teachers and students of Accountancy course of a private higher education institution on the professional 
accounting? For this, the aim of this study was to analyze the view of the professors and students of the course of Accounting of a private education institution in relation to the accounting professional. The methodology used to carry out this work questionnaires were administered to two groups, one for teachers and the other students. The results show that the majority of surveyed teachers have the title of specialist or master, with accounting training and seeking further training. Regarding the students surveyed, it was found that most works in accounting and wish to act as accounting business.

Keywords: accounting professional, perception, teachers and students.

\section{INTRODUÇÃO}

O ingresso cada vez maior de pessoas no ensino superior tem sido possível com a participação do capital privado. Para ilustrar isso, basta observar que o acesso à educação superior foi ampliado pelo crescente número de instituições privadas de ensino que, autorizadas e reconhecidas pelas autoridades governamentais, passaram a oferecer à sociedade, nas últimas décadas, a oportunidade da educação superior (OLIVEIRA; NETO; DANTAS 2008).

O desenvolvimento científico torna o mercado profissional muito competitivo, requisitando profissionais cada vez mais gabaritados. Nesse contexto, fazer um curso superior é o caminho adotado por pessoas que buscam um diferencial na qualificação profissional (DIAS; MOREIRA, 2008).

No curso de ciências contábeis, a formação do profissional necessita de muita experiência técnica, porém não se deve esquecer da construção do conhecimento a respeito da parte crítica. Conforme Nossa (1999), para que o professor exerça sua cidadania num projeto de educação torna-se necessário que ele seja um intelectual crítico capaz de apreender e trabalhar as diferenças visualizadas na sala de aula.

Diante desse contexto, se busca responder ao seguinte questionamento: qual a visão dos professores e estudantes do curso de Ciências Contábeis de uma instituição de ensino superior privada em relação ao profissional da contabilidade?

Para responder à questão de pesquisa proposta, o objetivo desse trabalho foi analisar a visão dos professores e estudantes do curso de Ciências Contábeis de uma instituição de ensino superior privada em relação ao profissional da contabilidade.

A profissão do contador encontra-se em constituição de um novo cenário em todo o mundo, colocando o objetivo da contabilidade direcionado a propiciar ao usuário, a avaliação da situação financeira da empresa, por meio dos métodos de mensuração e registro dos fatos econômicos. No Brasil, este cenário também se encontra em desenvolvimento, apesar de que 
no país ainda há evidências de que os profissionais contábeis tratam os assuntos relacionados aos clientes de uma forma precária, sendo que um dos pontos cruciais para o desenvolvimento da profissão é o foco no cliente. (MARION, 1998).

Na concepção de Barros (2005), as organizações buscam a eficiência e a eficácia, estando presentes em um ambiente de alta competitividade, havendo assim uma necessidade de se mostrar a relevância das informações contábeis para os usuários. Para que as informações contábeis sejam postas de forma a garantir eficiência e eficácia para o empresário, a academia deve desempenhar o seu papel, situado na formação dos profissionais contábeis, profissionais estes que devem ser dotados de conhecimento, competência, ética e responsabilidade social para que se possa informar as potencialidades das informações contábeis.

No contexto atual da educação destaca-se a profissão do contador, e como uma ciência necessita de estudos e pesquisas para melhor aproveitamento dos discentes no processo de ensino-aprendizagem na universidade. Além disso, pode-se perceber que diante da necessidade de competitividade instituída tanto pelos avanços tecnológicos, quanto pela exigência do cliente, se faz necessário entender qual a percepção dos profissionais da contabilidade sobre a profissão e o curso.

É importante a realização de um estudo exploratório sobre o perfil e a visão dos docentes dos cursos de contabilidade e dos estudantes que representam os futuros profissionais, para que então possa evidenciar alguns entraves na formação do profissional contador. Diante disso, fica clara a importância da profissão contábil e da formação dos profissionais dessa área, e assim a justificativa deste trabalho é tida pela importância do assunto para a classe contábil, bem como para as demais públicos interessados no assunto.

\section{REFERENCIAL TEÓRICO}

\subsection{Prática docente}

A arte de ensinar pode ser considerada uma das coisas mais importantes em um país, e encontra-se presente na vida das pessoas há muito tempo. Conforme Silva (2011), a educação existe no Brasil mesmo antes da chegada dos portugueses ao novo mundo, ocorria entre os próprios indígenas, eles já possuíam características próprias de educar em sua comunidade, esta educação se dava na prática e no cotidiano, ou seja, os índios menores observavam os adultos e treinavam aquela atividade. 
O aprendizado do aluno depende de vários fatores, sendo que um dos principais é o interesse do próprio discente, em que na visão de Dias e Moreira (2008), as Instituições de Ensino Superior (IES) devem transmitir o conhecimento aos discentes, para que estes estejam preparados para atuar no mercado de trabalho. Porém, a questão da preparação profissional não depende exclusivamente do ensino proporcionado pelas faculdades, mas também depende da atitude proativa do aluno em função do tipo profissional que pretende se tornar.

O estudo de André et al. (1999) mostra que a prática do professor em relação ao conjunto da sociedade evidenciam alguns pontos como as políticas neoliberais e educação, as relações entre educação e cultura, a construção de práticas educativas emancipatórias entre outras, e além desses pontos evidenciados, ainda há que se ressaltar o fato de que, muitos trabalhos mostram a importância da necessidade de articulação entre teoria e prática, no entanto, existe uma falta de dados empíricos para referenciar as práticas políticas educacionais, informando que há um tratamento isolado de disciplinas específicas e pedagógicas.

Ainda ressaltando a importância da teoria e prática, na visão de Andere e Araujo (2008) relacionar a teoria e prática é fator de garantia de competência para o exercício do magistério universitário, pois o processo de ensino-aprendizagem torna-se mais fácil quando o professor possui condições de trazer para a sala de aula dados efetivos da prática profissional e do mercado de trabalho.

Em um trabalho sobre as estratégias de ensino-aprendizagem no curso de graduação em Ciências Contábeis realizado por Mazzioni (2013), foi constatado que há uma convergência entre as estratégias preferidas pelos universitários e a estratégia utilizada pelos docentes, que tipicamente é realizada por meio de exposição oral dialogada, resolução de exercícios e realização de seminários, com o uso de recursos como o data show, quadro branco e laboratórios de informática.

\subsection{A formação do professor de Ciências Contábeis}

Os professores das diversas áreas têm o seu trabalho forçado a um nível de pesquisa elevado, pois são eles que irão orientar os futuros profissionais para atuarem na sociedade. André et al. (1999) analisaram trabalhos por meio de estudos e constataram que a formação continuada é concebida como formação em serviço, evidenciando ainda que o papel do professor passa também pelo lado profissional, estimulando-o a desenvolver meios inovadores de realizar seus trabalhos pedagógicos, com base na reflexão da prática. Dentro 
dessa ótica de pensamento, em que a formação continuada do professor se torna importante, cabe ressaltar a especificidade do professor de contabilidade.

Quando se fala no curso de Ciências Contábeis, estes docentes devem desenvolver profunda admiração pela pesquisa, em que serão postos a cada dia à situações diferentes e que exigem conhecimentos científicos atualizados, portanto devem se manter como conhecedores do assunto a ser ensinado para transmitirem informações cruciais aos discentes. Nossa (1999) descreve que no ensino superior, encontra-se muito a figura do professor transmissor de conhecimento, e o papel de relacionar o conteúdo específico com a relações práticas do mercado de trabalho deixa a desejar por parte da academia.

O professor de contabilidade tem de se apropriar das atividades do contador, para incluir em seu trabalho a perspectiva do desenvolvimento científico da contabilidade, assim como a visualização de ações da cultura, da ética, da inclusão e da responsabilidade profissional (LAFFIN, 2011). A exigência de professores com uma formação mais completa é imposta pelo mercado e, principalmente, pelas IES que seguem regras do MEC, o qual exige, segundo a Lei $n^{\circ}$ 9.394, art. 52, inciso II, pelos menos um terço do corpo docente das IES com titulação acadêmica de mestrado ou doutorado (ANDERE; ARAUJO, 2008).

\subsection{0 curso de Ciências Contábeis}

Para Costa (1988) a inexistência de infraestrutura satisfatória, inclusive física e material, além de bibliotecas e laboratórios, capazes de propiciar condições de realização de pesquisas e estudos avançados, não permite que esse elevado contingente de professores pagos em regime de tempo integral proporcionem o retorno adequado em termos de produção técnico-científica.

O projeto pedagógico dos cursos de graduação tem grande importância para a formação do profissional na universidade, Sachuk e Shinzaki (2007) identificaram em três instituições de ensino superior que nos projetos pedagógicos dos cursos existem vários fatores como a expansão no setor de serviços, a formação de competências, a educação tecnológica, entre outros, constatando que nas instituições pesquisadas, há fortes indícios de que os projetos pedagógicos dos cursos de Ciências Contábeis são apenas depositários de conhecimentos básicos e/ou técnicos, sendo de baixa qualidade no que tange à criação de novos conhecimentos, já que essa é uma das características mais importantes da ciência, a geração de novos conhecimentos. Esses projetos pedagógicos fazem parte da composição das instituições de ensino superior, já que neles são depositados todas as abordagens que devem ser instituídas durante os cursos de graduação. 
Uma das primeiras escolas a instalar um curso de Ciências Contábeis organizado no Brasil foi a Escola de Comércio Âlvares Penteado, em 1902. Inicialmente denominada de Escola Prática de Comércio, esta escola ofereceu um curso de duração de três anos, destinado à formação de guarda-livros (FAVERO, 1987). Beuren et al. (2009) ressaltam que a evolução das ciências contábeis no Brasil teve um estímulo que veio por meio da criação de cursos de graduação e pós-graduação tanto lato quanto stricto sensu. O primeiro programa de pósgraduação com um curso de doutorado na área de Contabilidade foi instalado na década de 1970 em São Paulo, ofertado pela FEA/USP - Faculdade de Economia, Administração e Contabilidade da Universidade de São Paulo.

Ao ingressar no curso superior de ciências contábeis, o aluno consegue captar a informação principal, que pode ser entendida pela gestão do patrimônio. Diante da abrangência do referido curso, os discentes possuem diversas opções de atuação ao final dos oito semestres de graduação, que vai desde a área administrativa até áreas mais específicas como auditoria, custos e a própria contabilidade financeira. Isso se deve pelo fato de ser algo que abre as portas do mercado de trabalho para as pessoas, pois elas podem escolher em que irão atuar. Além disso, Oliveira, Neto e Dantas (2008) ressaltam que a avaliação da qualidade do ensino é uma questão recorrente e deve fazer parte das preocupações de todos aqueles que estão inseridos nessa atividade.

Segundo Marion (2005), o profissional da contabilidade tem uma das funções mais responsáveis da empresa, devendo então estar sempre atualizado, pois ele irá realizar trabalhos que exigem conhecimento sobre as operações que serão realizadas na empresa além de elaboração de registros para fornecer a informação ao empresário, o auxiliando na tomada de decisões. Em uma pesquisa para averiguar o currículo dos cursos de Ciências Contábeis, Czesnat, Cunha e Domingues (2009) constatou que existe um alto grau de similaridade entre o os currículos pesquisados e o currículo mundial proposto pela ONU/Unctad/Isar, mas que apesar disso, a maioria dos cursos não considera a disciplina de contabilidade internacional como obrigatória, demonstrando normalmente a formação dos profissionais contábeis tem foco nos mercados internos.

Lousada e Martins (2005) realizaram um estudo com o objetivo de mostrar a importância do planejamento e desenvolvimento de sistemas de acompanhamento de egressos de uma instituição de ensino superior, e constataram que há um reconhecimento por parte dos dirigentes das instituições para essa necessidade de acompanhamento por meio dessa prática com egressos dos cursos de graduação em ciências contábeis. Essa prática de 
acompanhamento pode evidenciar tanto os pontos fortes como os pontos fracos da instituição de ensino superior, e posteriormente utilizar esse acompanhamento como algo que possa melhorar o desenvolvimento do curso de graduação.

Para poder caracterizar o ensino da contabilidade no Brasil, identificar e analisar seus problemas e apontar soluções, é relevante que se apresentem os aspectos históricos do sistema educacional contábil brasileiro (VESCO, 2006). Diante desse contexto, vale salientar que o curso de ciências contábeis é uma das mais antigas graduações existentes no país. O quadro a seguir mostra a história e a evolução da educação na área de ciências contábeis no Brasil:

No século $\mathrm{XX}$, foi dada também a criação dos cursos de pós-graduação stricto e lato sensu nas áreas específicas de contabilidade, em que na cidade de São Paulo, já estava sendo lançado o curso de Doutorado em Ciências Contábeis da FEA/USP, considerado o programa pioneiro de pós-graduação em contabilidade do país. Já na capital do Brasil e nas capitais de alguns estados do nordeste houve a expansão com o programa de pós-graduação interinstitucional, além dos cursos em outros estados como no Rio de Janeiro, Rio Grande do Sul, Fortaleza e outras capitais do país (PELEIAS et al., 2007).

Sobre a atuação dos professores e permanência dos estudantes universitários nas instituições, Dias (2010) mostra que no momento da aprendizagem deve haver a aquisição de um conjunto de conhecimentos, técnicas e métodos de forma crítica por parte do aluno. Desta maneira, é possível que a formação dos alunos, que representam os futuros profissionais, esteja condicionada a uma interação entre docentes e discentes, em que deve haver o fator principal, conhecido como interesse por parte dos alunos. Em um estudo sobre o desempenho dos estudantes do curso de Ciências Contábeis, Silva (2008) aponta que existem várias mudanças que são necessárias para o ensino nessa área, e uma delas é que o ensino deve deixar de ser focado no professor para centrar-se no aluno.

Lacerda, Reis e Santos (2008) com intuito de analisar os fatores condicionantes da motivação e permanência dos alunos nos cursos de graduação em Ciências Contábeis de uma instituição de ensino superior, utilizaram a teoria dos dois fatores de Herzberg, que versa sobre os fatores extrínsecos e intrínsecos, e encontrou que entre os fatores intrínsecos, um dos mais relevantes foi a interação entre alunos e professores, corroborando com o que o autor Dias (2010) entende quando evidencia a importância da interação entre docentes e discentes.

Em relação aos fatores extrínsecos, Lacerda, Reis e Santos (2008) constataram que a possibilidade de ingresso no mercado de trabalho é o fator mais importante para a 
permanência do aluno no curso de graduação, e tratam ainda que esses resultados são importantes para as instituições de ensino superior.

\section{METODOLOGIA}

Este trabalho se propôs a analisar a visão dos professores e estudantes do curso de Ciências Contábeis de uma instituição de ensino superior privada em relação ao profissional da contabilidade. Para tanto, foram realizadas pesquisas bibliográficas e uma pesquisa empírica com aplicação de questionários na cidade de Juazeiro do Norte, localizada estrategicamente no centro do nordeste.

Este trabalho trata-se de uma pesquisa de natureza quantitativa, visto que utiliza-se de investigação por meio de questionários, sendo realizado com rigor metodológico para que seja válido.

A metodologia do processo de ensino e aprendizagem busca fortalecer a integração teoria e prática valorizando a experiência prévia do aluno (RIVAS, CONTE; AGUILAR, 2007). Por este motivo se faz necessário a investigação da visão dos professores e estudantes do curso de Ciências Contábeis, analisando as suas bases de formação.

Para realização desta pesquisa, foram utilizados questionários com perguntas objetivas, aplicados em dois tipos de públicos: professores do curso de Ciências Contábeis e estudantes do último semestre do curso de Ciências Contábeis de uma Instituição de Ensino Superior da cidade de Juazeiro do Norte.

Em relação ao grupo de professores pesquisados, a população foi de 26 docentes, e foram colhidos 8 questionários respondidos, representando 30\% do total. Já em relação ao grupo de estudantes pesquisados, a população foi de 17 discentes, em que foram colhidos 8 questionários respondidos, o que representa $47 \%$ do total, sendo que as amostras da pesquisas podem ser consideradas representativas por representarem mais de $30 \%$ da população a qual se refere.

Os itens dos questionários aplicados aos professores do curso de Ciências Contábeis abordaram os assuntos: nível e área de formação; área de atuação; formação complementar continuada; visão sobre a profissão de contabilidade; utilização de tecnologias no exercício da docência; e importância do conhecimento para o profissional formado.

Em relação aos questionários aplicados aos alunos do curso de graduação em Ciências Contábeis, foram abordados os seguintes assuntos: área de atuação profissional; área desejada para seguir após a graduação; motivos pela escolha do curso; visão em relação ao mercado de 
trabalho; visão em relação ao ensino ofertado pela instituição; e importância do conhecimento para o profissional.

A pesquisa teve como tema final para discussão a apresentação e análise dos dados acerca das duas dimensões pesquisas: professores e alunos. A análise foi realizada avaliando a visão dos docentes entrevistados com as características desejáveis pelos estudantes para o futuro profissional da contabilidade.

\section{APRESENTAÇÃO E ANÁLISE DOS DADOS}

Os resultados da pesquisa são apresentados a seguir, sendo os questionários aplicados aos professores do curso de graduação em Ciências Contábeis apresentados primeiramente, e logo após os questionários aplicados aos alunos do curso de graduação em Ciências Contábeis.

Os questionários aplicado aos professores evidenciaram o perfil e as características dos professores do curso de graduação em Ciências Contábeis de acordo com o nível e a área de formação, a área de atuação, a formação complementar continuada, a visão sobre a profissão de Contabilidade, a utilização de tecnologias no exercício da docência e a importância do conhecimento para o profissional formado na área de contabilidade.

Gráfico 1 - Nível de formação do docente.

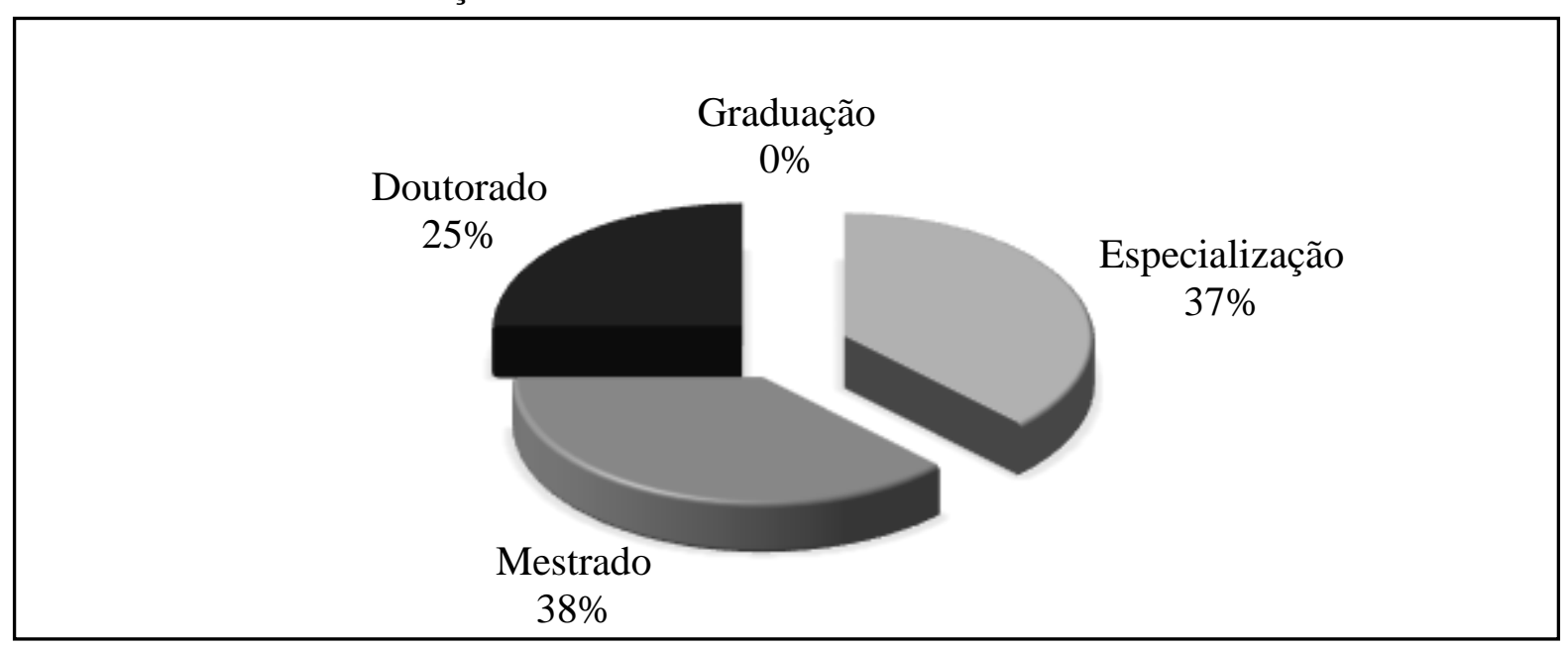

Fonte: Dados da pesquisa 2014.

De acordo com o gráfico 1, foi encontrado que em relação ao nível de formação do docente, a maioria dos professores pesquisados possuem tíitulo de especialização (37\%) ou de 
LEAL, P. H.; COSTA, B. M. DO N.; SANTOS, B. F. DOS. O perfil do profissional contábil a partir da visão de professores e alunos de uma instituição de ensino superior. Revista Unemat de Contabilidade2, v. 6, n. 11, 2017.

mestre (38\%), seguido por professores doutores (25\%), ao passa em que nenhum dos professores pesquisados tem apenas a graduação como nível de formação.

Esses resultados evidenciam que existe um nível razoavelmente bom em relação a formação dos professores da instituição pesquisada, pois dos professores pesquisados nenhum possui apenas o título de graduado, podendo indicar que a maioria dos professores da instituição são mestres ou doutores. Um quadro de docentes composto por mestres e doutores proporciona uma ponte de acesso à pesquisa para os alunos, visto que isso pode levar a um incentivo maior à produção científica na instituição, sendo um ponto positivo para a formação do profissional quando relacionado à pesquisa.

Gráfico 2 - Área de formação do docente.

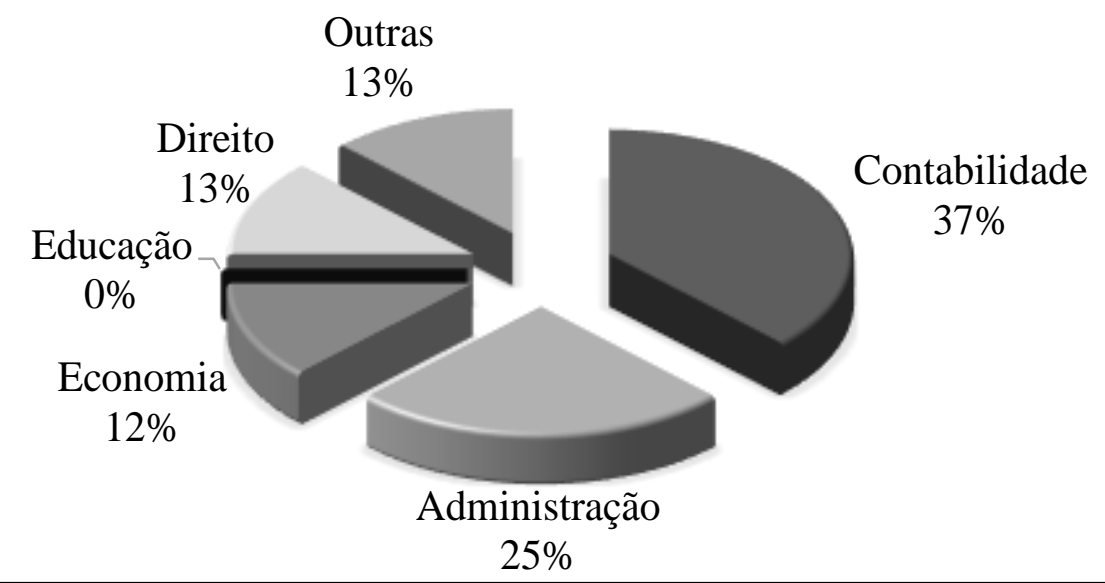

Fonte: Dados da pesquisa 2014.

O gráfico 2 evidencia a área de formação do docente, sendo constatado que, a maioria possui formação em contabilidade (37\%), seguida por administração (24\%) e logo depois economia (13\%), direito (13\%) e outras áreas de formação (13\%).

Pode ser constatado que dos oito professores pesquisados, três possuem formação específica em contabilidade, sendo a maioria dos pesquisados, caracterizando que o curso de graduação da instituição pesquisada é mais focalizado na gestão e na própria especificidade da contabilidade.

A formação específica do quadro de professores é importante para o futuro profissional que sairá da instituição, além disso, é preciso levar em consideração o conceito da interdisciplinaridade, que orienta o professor a abordar todos os assuntos relacionados par melhor formação do aluno. 

professores e alunos de uma instituição de ensino superior. Revista Unemat de Contabilidade2, v. 6, n. 11, 2017.

Desta maneira, percebe-se que a formação específica da maioria dos professores da instituição pesquisada acaba proporcionando sólida formação básica para os futuros profissionais contábeis. Além disso, permite-se dizer que as demais áreas de formação de outros professores como administração, econômica e direito conferem diversificação de aspectos do ensino do profissional contábil, garantindo a experiência do ensino multidisciplinar diante de docentes com formação diversificada.

Gráfico 3 - Formação continuada dos docentes.

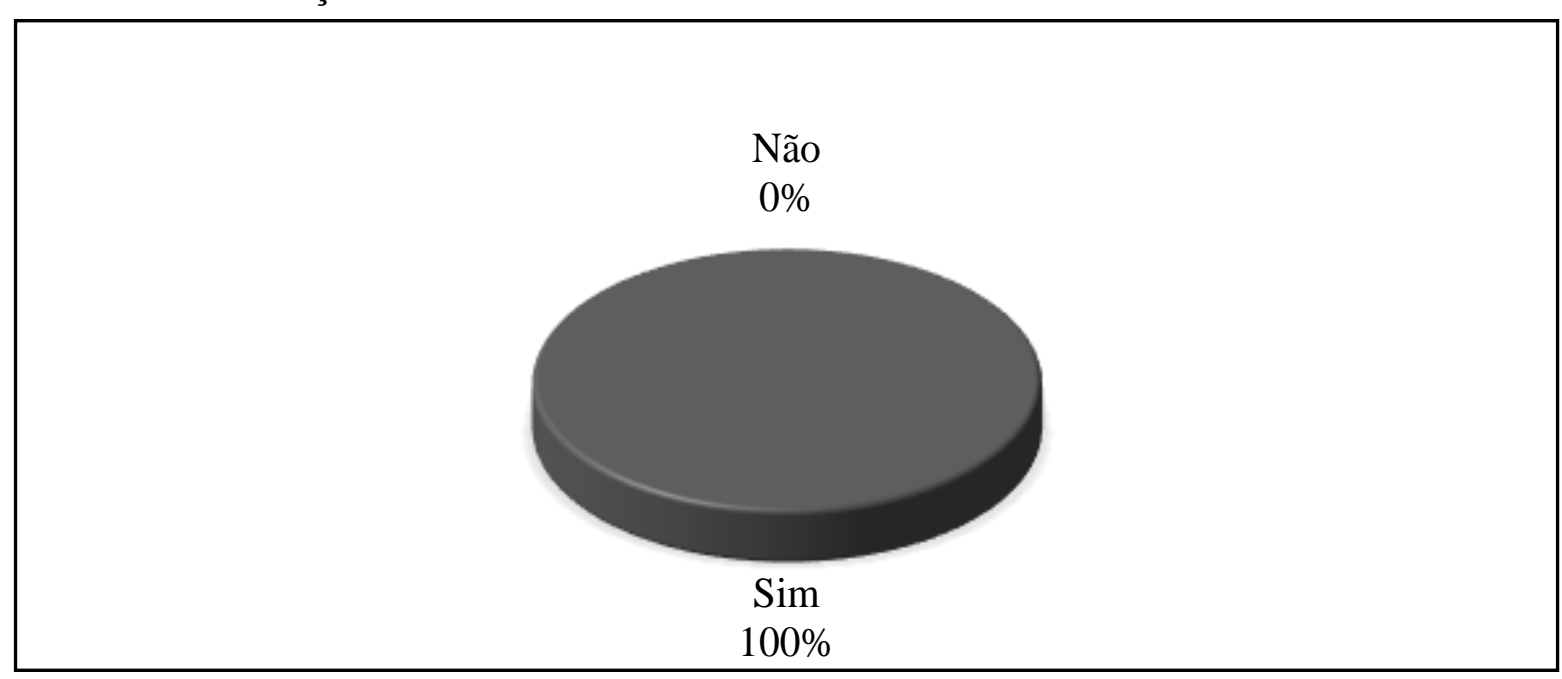

Fonte: Dados da pesquisa 2014.

Em relação ao gráfico 3 que versa sobre a atitude dos docentes em uma busca por formação complementar continuada, foi evidenciado que todos os oito professores pesquisados $(100 \%)$ responderam que sim, indicando que os docentes da instituição pesquisada procuram se aperfeiçoar e estar sempre atualizados. Diante desse resultado, podese inferir que os professores da instituição estão desempenhando seu papel, visto que a busca por formação continuada pode ser vista como um comprometimento dos próprios professores com a formação do profissional de contabilidade. 
Gráfico 4 - Opinião dos docentes sobre o futuro da profissão contábil.

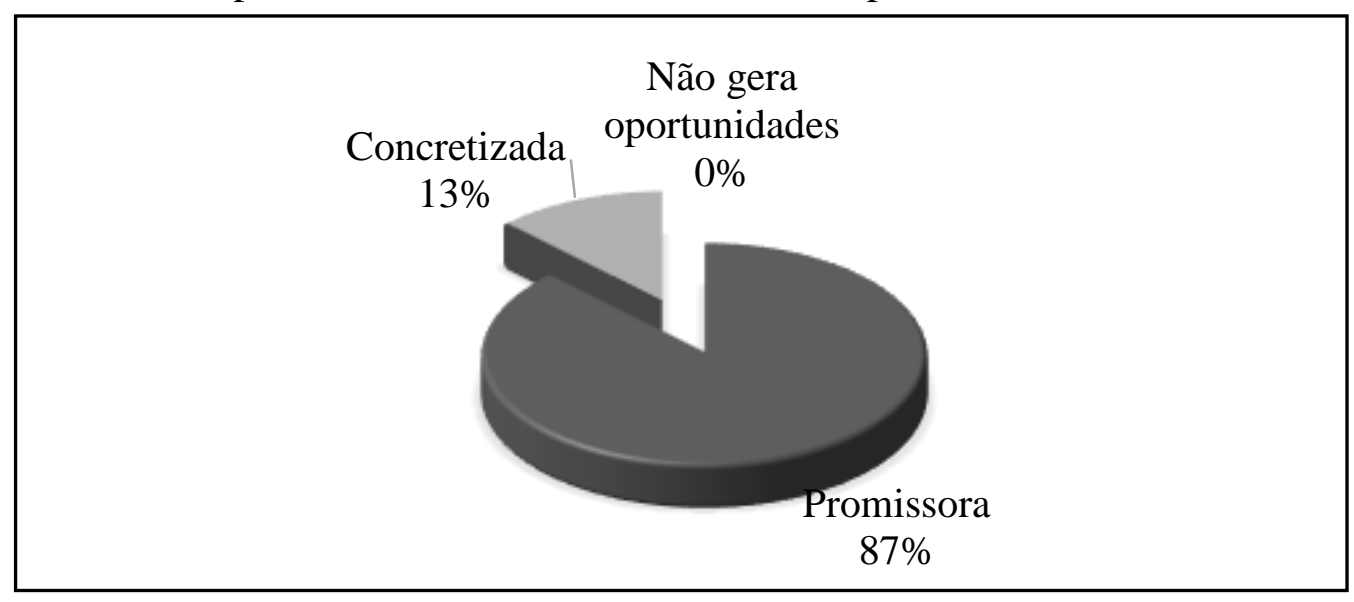

Fonte: Dados da pesquisa 2014.

Em relação ao gráfico 4, os respondentes da pesquisa informaram que a maioria (87\%) considera que o futuro da profissão contábil é promissor, e apenas (13\%) considera que a profissão já está concretizada, dando assim mais responsabilidades para os futuros profissionais de contabilidade, que não podem ver a profissão como algo que já está concretizado, tendo assim que aumentar ainda mais o empenho para que se desenvolva na profissão que tem um futuro promissor.

Gráfico 5 - Metodologia de ensino mais utilizada pelo docente na sala de aula.

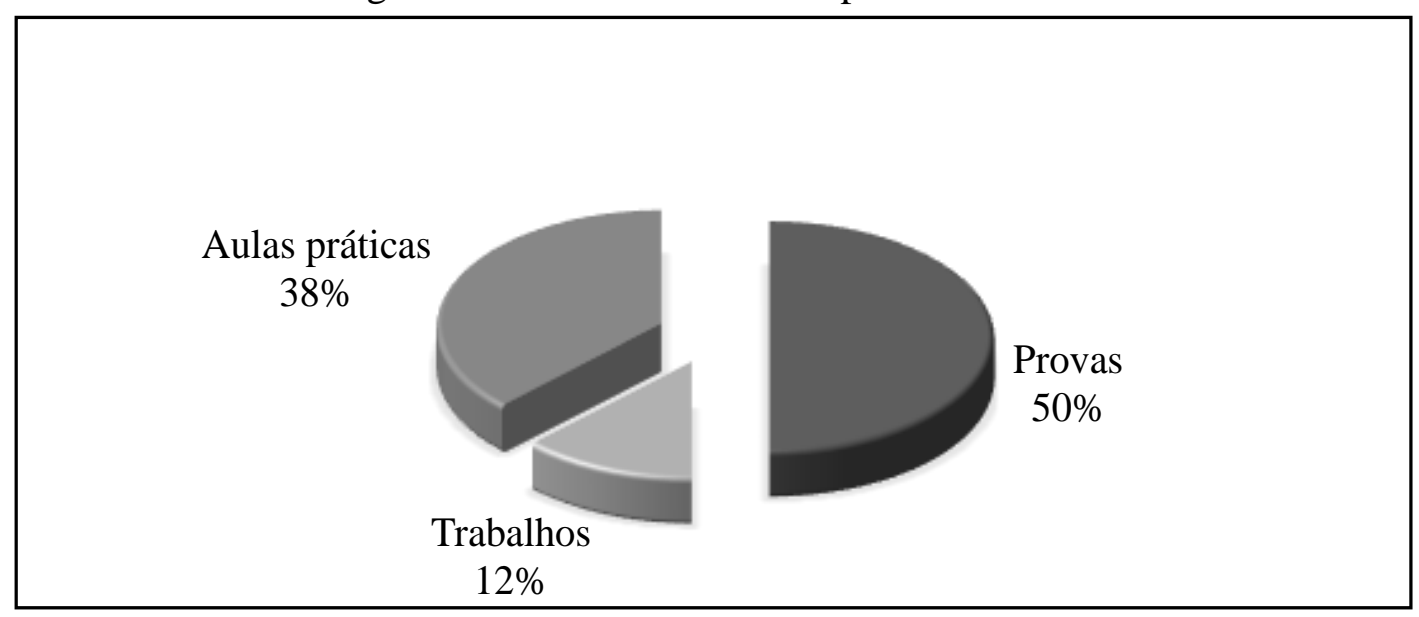

Fonte: Dados da pesquisa 2014. 
O gráfico 5 representa a metodologia utilizada pelo professor em sala de aula, sendo que a maioria dos docentes (49\%) utilizam a aplicação de provas, seguido pelas aulas práticas (38\%) e por último, apenas $13 \%$ realiza a aplicação de trabalhos.

Diante disso, pode-se constatar que as aulas práticas, são realizadas com uma frequência regular no curso e na instituição de ensino pesquisada, o que pode ser considerado uma falha, visto que as aulas práticas proporcionam aos alunos uma aproximação com o que deve ser desempenhado na vida profissional do profissional de contabilidade, logo, elas deveriam ser utilizadas com maior frequência pelos professores.

Gráfico 6 - Principal importância para o futuro profissional contábil na visão dos docentes.

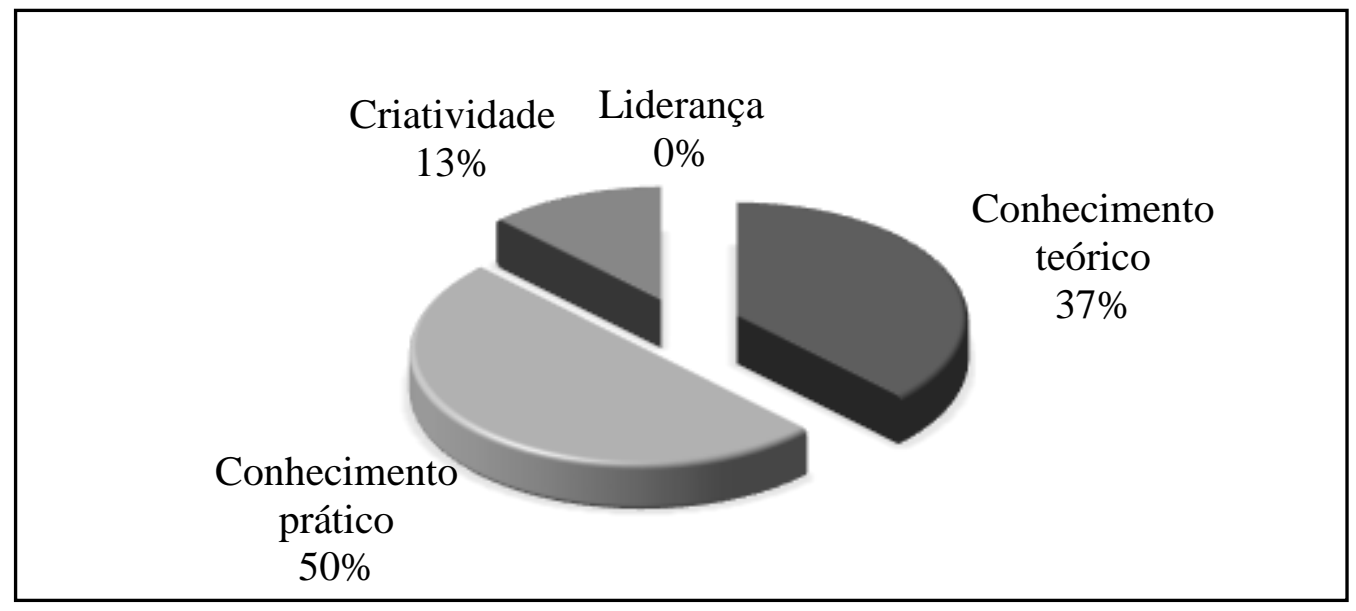

Fonte: Dados da pesquisa 2014.

De acordo com o gráfico 6, em que foi visto que a maior parte dos professores pesquisados (49\%) consideram que a principal importância para o futuro profissional de contabilidade é o conhecimento prático, seguido pelo conhecimento teórico com $38 \%$ e por último a criatividade com apenas $13 \%$, sendo que nenhum dos pesquisados considera a liderança como de grande importância para o profissional de contabilidade. Pode-se constatar que os docentes consideram o conhecimento prático como o que há de maior importância para o profissional da área contábil, sendo que este conhecimento é o que tem maior possibilidade de ser definitivo na vida profissional. O conhecimento teórico também é muito importante para o contador, pois, todas as práticas realizadas na execução do trabalho desse profissional, são decorrentes de experiências e conhecimentos científicos aprendidos e trabalhados durante todo o período de graduação vivido na academia. 

professores e alunos de uma instituição de ensino superior. Revista Unemat de Contabilidade2, v. 6, n. 11, 2017.

O questionário aplicado aos estudantes do último semestre do curso de graduação em Ciências Contábeis da instituição de ensino superior pesquisada evidenciou o perfil e a visão dos discentes de acordo com a área de atuação profissional, a área desejada para seguir após a graduação, os motivos pela escolha do curso, a visão em relação ao mercado de trabalho, a visão em relação ao ensino ofertado pela instituição, e a importância do conhecimento para o profissional.

Gráfico 7 - Área de atuação profissional dos alunos pesquisados.

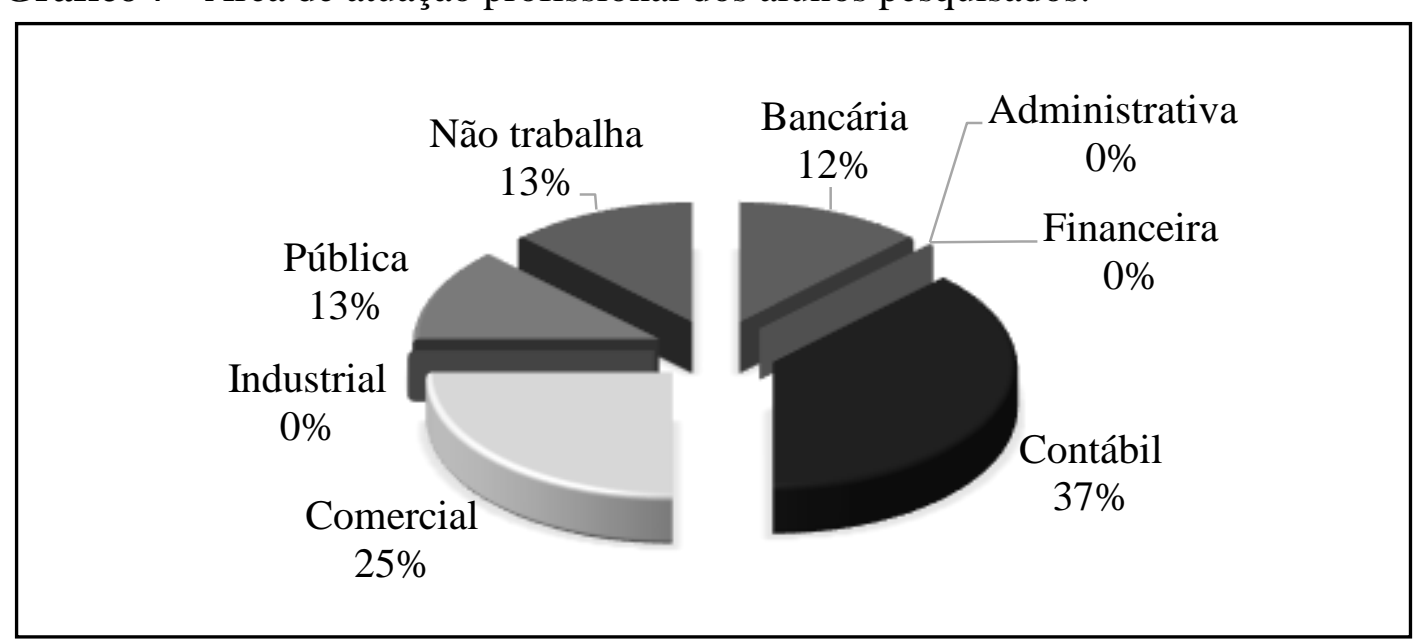

Fonte: Dados da pesquisa 2014.

De acordo com o gráfico 7, a maioria dos estudantes do último semestre do curso de graduação em Ciências Contábeis da instituição de ensino pesquisada atuam na área contábil (37\%), seguido por atuantes na área comercial (24\%), pública (13\%), bancária (13\%) e por último que não trabalha (13\%). Esses dados permitem afirmar que a maioria dos discentes pesquisados atuam na área de contabilidade, o que pode ser um bom sinal, pois a atuação na área específica de contabilidade proporciona uma conexão dos conhecimentos gerados e adquiridos em sala de aula com os conhecimentos da vida prática do mercado de trabalho. 

professores e alunos de uma instituição de ensino superior. Revista Unemat de Contabilidade2, v. 6, n. 11, 2017.

Gráfico 8 - Área de atuação desejada pelo aluno a ser seguida após a conclusão da graduação.

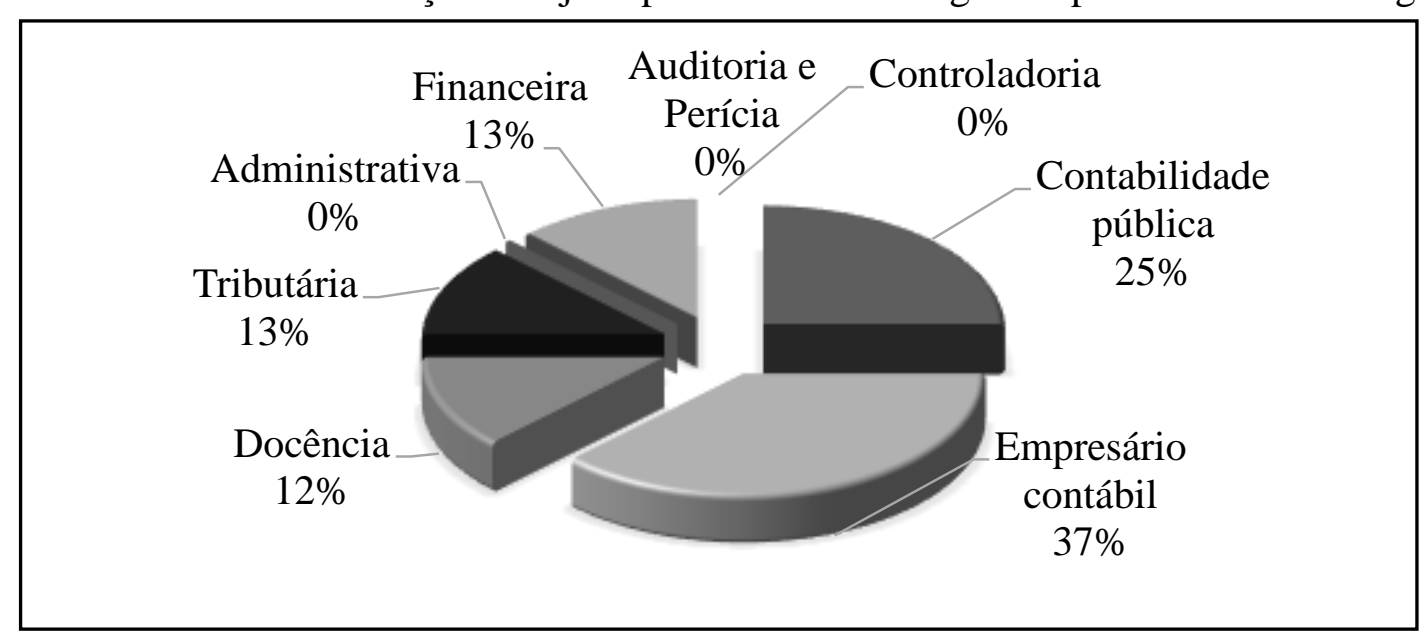

Fonte: Dados da pesquisa 2014.

O gráfico 8 que evidencia a área a ser seguida pelo discente após a conclusão da graduação mostrou que, a maioria dos pesquisados (37\%) pretende atuar como empresário de contabilidade, seguido pelo desejo em atuação na contabilidade pública (24\%), tributária (13\%), financeira (13\%) e por último docência (13\%).

Esses resultados podem indicar que a maioria dos discentes pretende ser empresário contábil, e para isto, é necessário que se tenha experiências específicas na área de contabilidade, logo, de acordo com o gráfico 7, maior parte dos discentes já atua na área específica de contabilidade, sendo que isso proporciona a aquisição de experiências por meio da vida prática no mercado de trabalho.

Já em relação ao desejo pela atuação na contabilidade pública, pode representar um viés dos discentes para a preparação e dedicação a estudos relacionados a concursos públicos no intuito de atuar na área pública como profissional de contabilidade. Em relação a área tributária, pode-se constatar que os discentes que atuam na área específica de contabilidade, também de acordo com o gráfico 7 representam uma tendência ao desenvolvimento também na área tributária, a qual faz parte da própria atuação dos profissionais de contabilidade. 

professores e alunos de uma instituição de ensino superior. Revista Unemat de Contabilidade2, v. 6, n. 11, 2017.

Gráfico 9 - Motivos da escolha pelo curso de acordo com os estudantes pesquisados.

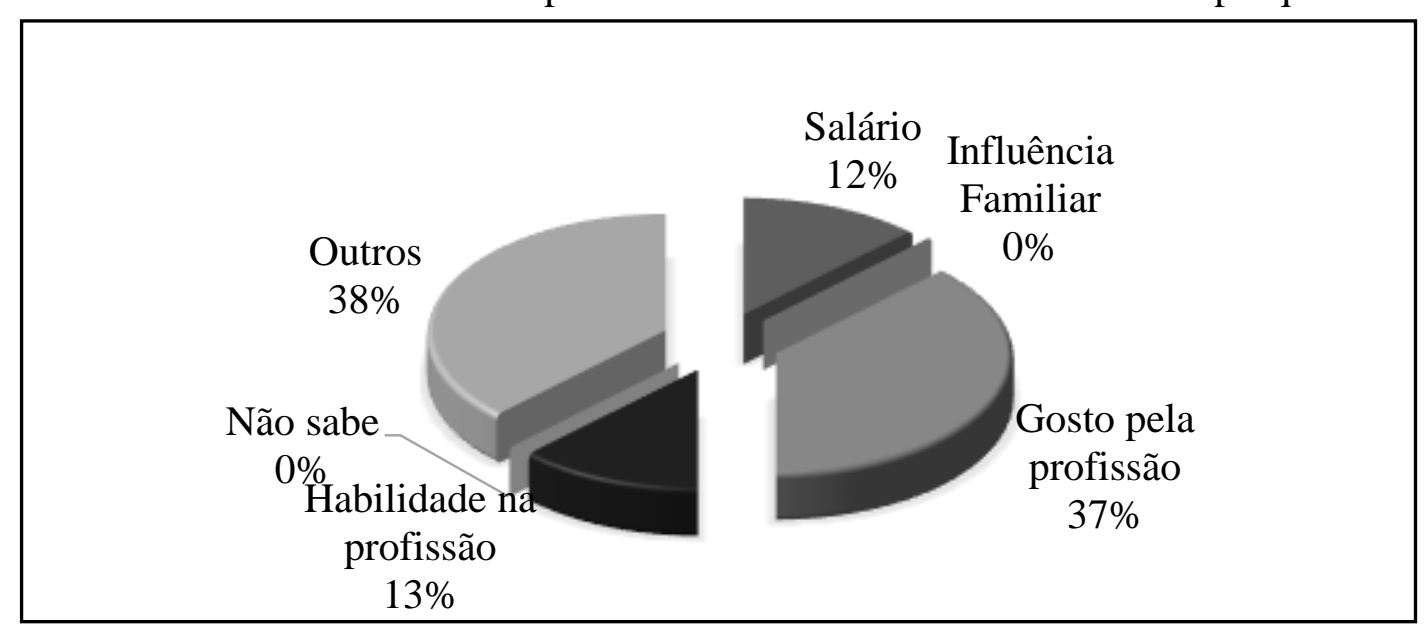

Fonte: Dados da pesquisa 2014.

Em relação ao gráfico 9, a maioria dos discentes informam que a escolha pelo curso de Ciências Contábeis se deve pelo gosto pela profissão (37\%) e por outros motivos (37\%), seguido pelo salário (13\%) e pela habilidade com a profissão (13\%). De acordo com os resultados acima, pode-se constatar que o gosto pela profissão como um dos motivos pela escolha pelo curso pode ser determinante no desempenho do discente tanto na academia, quanto no mercado de trabalho, pois isso pode indicar um comprometimento maior por parte dos discentes, e consequentemente uma atuação com maior dedicação, fazendo com que se isso se torne um diferencial do profissional, influenciado pelo gosto e pela vontade de ser da área contábil. Em relação ao salário, este pode ser um dos fatores condicionantes para a escolha de um curso de graduação, porém foi visto que o salário não é o fator que tem maior peso nessa escolha. 

professores e alunos de uma instituição de ensino superior. Revista Unemat de Contabilidade2, v. 6, n. 11, 2017.

Gráfico 10 - Visão do estudante quanto ao mercado de trabalho para o profissional contábil.

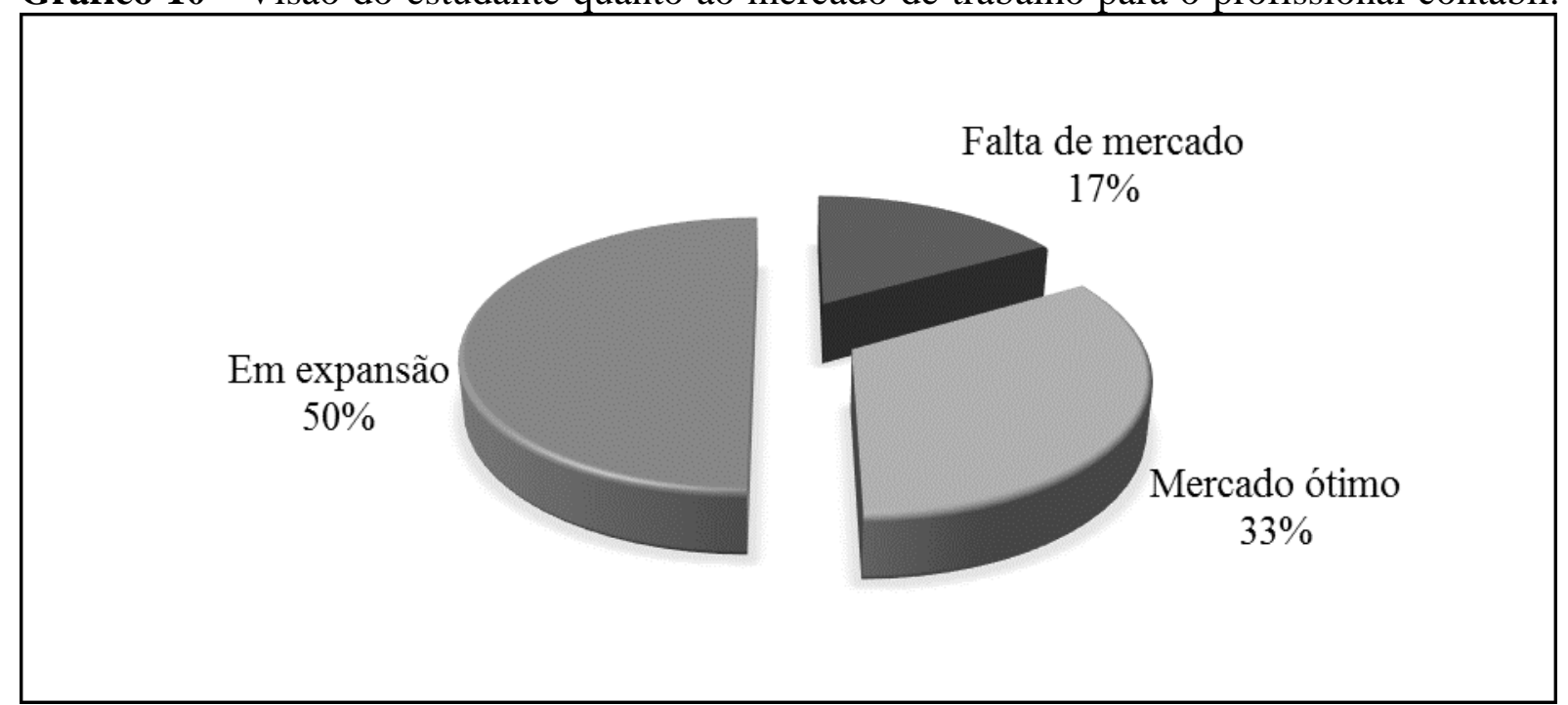

Fonte: Dados da pesquisa 2014.

O gráfico 10 que informa a visão do discente em relação ao mercado de trabalho, evidencia que a maioria dos estudantes representada por $75 \%$ acredita que o mercado do profissional contábil está em expansão, seguido pela visão de mercado ótimo por $25 \%$ dos estudantes pesquisados.

Gráfico 11 - Visão do discente em relação ao ensino ofertado pela instituição.

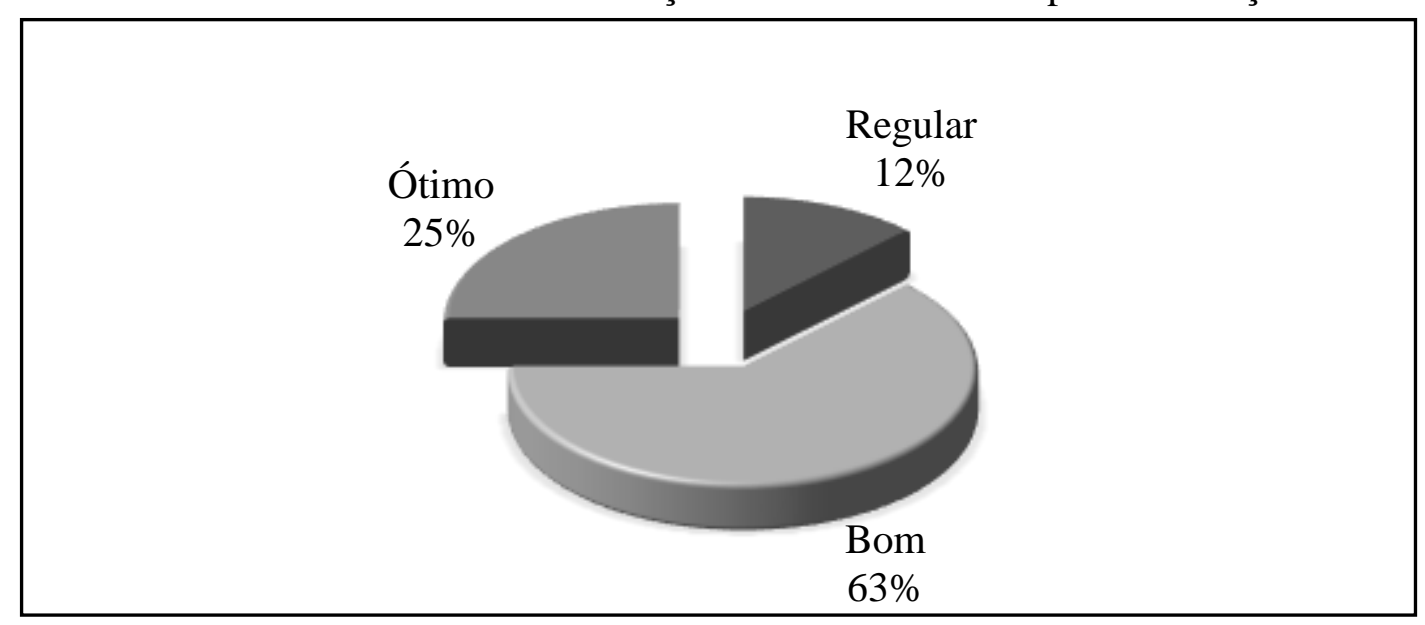

Fonte: Dados da pesquisa 2014.

Em relação ao gráfico 11, que evidenciou a visão do estudante em relação ao ensino ofertado pela instituição, foi visto que a maioria avaliou o ensino como bom (62\%) seguido por estudantes que avaliaram o ensino como ótimo (25\%) e por último, o estudantes que avaliaram o ensino da instituição como regular (13\%). De acordo com o disposto, a maioria 
dos discentes classifica o ensino da instituição pesquisada como bom, sendo um indicativo positivo para a instituição, mas que ainda pode ser melhorado para que a avaliação do ensino possa ser considerada ótima pelos estudantes.

Gráfico 12 - Principal importância para o futuro profissional de contabilidade na visão dos estudantes.

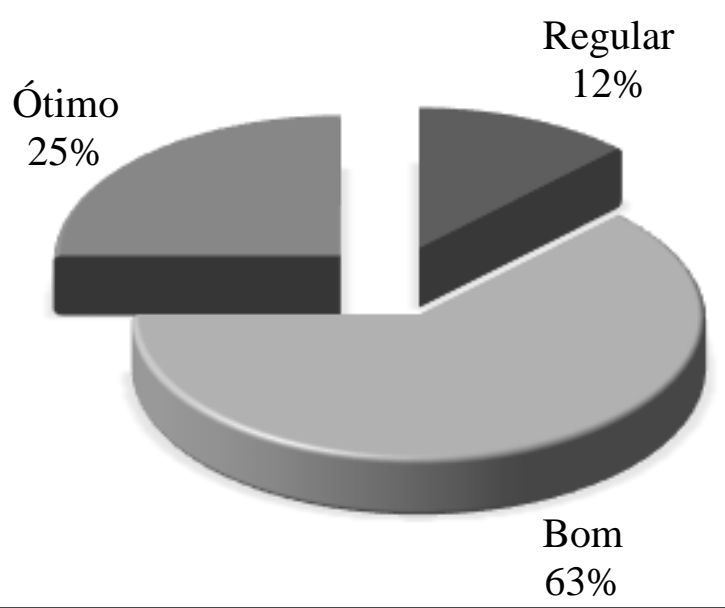

Fonte: Dados da pesquisa 2014.

De acordo com o gráfico 12, é evidenciado que a maioria dos discentes pesquisados consideram a criatividade (34\%) como o fator mais importante para o futuro profissional de contabilidade, seguido pela liderança (33\%), conhecimento prático (22\%) e por último conhecimento teórico (11\%). Diante desses resultados, pode-se constatar que a criatividade como o fator de maior importância para o futuro profissional da área contábil pode ser traduzida como o desenvolvimento de novas alternativas como a inovação, o que pode levar ao desenvolvimento não só do profissional, mas também da organização que este desempenha seu trabalho.

\section{CONSIDERAÇÕES FINAIS}

Este estudo teve como objetivo analisar o perfil do profissional contábil a partir da visão dos professores e dos alunos de graduação do último semestre do curso de Ciências Contábeis de uma instituição de ensino superior da cidade de Juazeiro do Norte.

Para tanto, foi realizada uma pesquisa com de aplicação de questionários a dois tipos de respondentes, primeiramente foram elaborados e aplicados os questionários aos docentes 
do curso citado, e posteriormente foram elaborados e aplicados os questionários aos discentes do curso citado.

De modo geral, verificou-se que a maioria dos professores possuem título de especialista ou de mestre, com formação específica em contabilidade, e que procuram desenvolver-se por meio de formação complementar continuada. Além disso, a maioria desses docentes acredita que o futuro da profissão contábil é promissor e que a principal importância para o futuro profissional de contabilidade é o conhecimento prático seguido pelo conhecimento teórico. Os docentes pesquisados ainda afirmam que utilizam com maior frequência em suas aulas, a aplicação de provas e aulas práticas.

Em relação aos discentes pesquisados, constatou-se que a maioria deles atua na área contábil e desejam atuar futuramente como empresários de contabilidade. Evidenciou-se ainda que o principal motivo pela escolha do curso de Ciências Contábeis foi o gosto pela profissão, e que a maioria dos pesquisados acreditam que o futuro da profissão contábil é promissor. Em relação ao ensino ofertado pela instituição, verificou-se que a maioria dos estudantes considera o ensino como bom, e consideram ainda que a principal importância para o futuro profissional de contabilidade é a criatividade.

Assim, pode-se considerar que o profissional contábil é visto como uma profissão promissora, pois além dos respondentes a considerarem como tal, a maioria dos professores da instituição pesquisada estão em busca de formação continuada. Além disso, a maioria dos estudantes da instituição informaram que atua na área contábil, além de estarem satisfeitos com o ensino ofertado pela instituição, levando a entender que o profissional contábil pode ter um futuro promissor.

Diante do exposto, o trabalho realizado apresenta algumas limitações em relação ao número de respondentes da categoria docente, recomenda-se para estudos futuros, uma análise mais detalhada e que contemple um número maior de respondentes para que a pesquisa se torne mais representativa.

\section{REFERÊNCIAS}

ANDERE, Maira Assaf. ARAUJO, Adriana Maria Procópio de. Aspectos da formação do professor de ensino superior de Ciências Contábeis: uma análise dos programas de pósgraduação. R. Cont. Fin.: USP. v. 19, n. 48, p. 91-102, set./dez. 2008.

ANDRÉ, Marli; SIMÕES, Regina H.S.; CARVALHO, Janete M.; BRZEZINSKI, Iria. Estado da arte da formação de professores no Brasil. Revista de Educação \& Sociedade, ano 20, n. 68, Dez. 1999. 
LEAL, P. H.; COSTA, B. M. DO N.; SANTOS, B. F. DOS. O perfil do profissional contábil a partir da visão de professores e alunos de uma instituição de ensino superior. Revista Unemat de Contabilidade2, v. 6, n. 11, 2017.

BARROS, Vaine de Magalhães. O novo velho enfoque da informação contábil. Revista de Contabilidade e Finanças da USP, n. 38, p. 102-112, maio/ago. 2005.

BEUREN, Ilse Maria; NASCIMENTO, Sabrina do; SANTOS, Vanderlei dos; RENGEL, Silene. Redes de pesquisa entre os egressos do doutorado em Ciências Contábeis da FEA/USP. Revista de Contabilidade, Gestão e Governança, v. 12, n. 3, p. 72-86, set/dez 2009.

COSTA, José Mário Ribeiro da. O Ensino da contabilidade na universidade brasileira: quem é e como pensa o seu corpo docente. 1988. 108 f. Dissertação (Mestrado em Ciências Contábeis) - Instituto Superior de Estudos Contábeis, Fundação Getúlio Vargas do Rio de Janeiro, Rio de Janeiro, 1988.

CZESNAT, Aline Oliveira; CUNHA, Jacqueline Veneroso Alves da; DOMINGUES, Maria José Carvalho de Souza. Análise comparativa entre os currículos dos cursos de Ciências Contábeis das universidades do estado de Santa Catarina listadas pelo MEC e o currículo mundial proposto pela ONU/UNCTAD/ISAR. Revista de Gestão \& Regionalidade, v. 25, n. 75, p. 22-30, set/dez, 2009.

DIAS, Cláudio Marcos Praxedes. A formação do professor de ciências contábeis: a importância do aprendizado para a docência. 2010. 92 f. Dissertação (Mestrado em Educação) - Programa de Pós-Graduação em Educação, Universidade Federal de Sergipe, São Cristóvão, 2010.

DIAS, L.M.S., MOREIRA, A.C.S. As perspectivas da profissão contábil para os formandos em ciências contábeis do instituto de estudos superiores da Amazônia - IESAM. $18^{\circ}$ CONGRESSO BRASILEIRO DE CONTABILIDADE. Cód. do trab. 482. Anais... Gramado, 2008.

FAVERO, Hamilton Luiz. O ensino superior de ciências contábeis no do estado do Paraná estudos de casos. 1987. 428 f. Dissertação (Mestrado em Ciências Contábeis) - Instituto Superior de Estudos Contábeis, Fundação Getúlio Vargas do Rio de Janeiro, Rio de Janeiro, 1987.

LACERDA, Juliana Ramires; REIS, Sandra Melo dos; SANTOS, Nálbia de Araújo. Os fatores extrínsecos e intrínsecos que motivam os alunos na escolha e na permanência no curso de Ciências Contábeis: um estudo da percepção dos discentes numa universidade pública. Rev. Ref. Cont. da UEM, v. 27, n. 1, jan./abr. 2008.

LAFFIN, Marcos. Contabilidade e ensino: mediações pedagógicas. Florianópolis: Núcleo de Publicações do CED/UFSC, 2011.

O professor de contabilidade no contexto de novas exigências. Revista Brasileira de Contabilidade, Brasília, n. 127, 2001.

LOUSADA, Ana Cristina Zenha; MARTINS, Gilberto de Andadre. Egressos como fonte de informação à gestão dos cursos de Ciências Contábeis. Revista de Contabilidade e Finanças da USP, n. 37, p. 73-84, jan./abr. 2005.

MARION, José Carlos. Contabilidade Empresarial. 11.Ed. - São Paulo: Atlas, 2005. 
LEAL, P. H.; COSTA, B. M. DO N.; SANTOS, B. F. DOS. O perfil do profissional contábil a partir da visão de professores e alunos de uma instituição de ensino superior. Revista Unemat de Contabilidade2, v. 6, n. 11, 2017.

Preparando-se para a profissão do futuro. Revista de Contabilidade Vista \& Revista Belho Horizonte, v. 9, n. 1, p. 14-21, mar. 1998.

MAZZIONI, Sady. As estratégias utilizadas no processo de ensino-aprendizagem: concepções de alunos e professores de Ciências Contábeis. Revista Eletrônica de Administração e Turismo, v. 2, n. 1, p. 93-109, jan./jun. 2013.

NOSSA, Valcemiro. Ensino da contabilidade no Brasil: uma análise crítica da formação do corpo docente. 1999. 158 f. Dissertação (Mestrado em Controladoria e Contabilidade) Programa de Pós-Graduação em Controladoria e Contabilidade, Universidade de São Paulo, São Paulo, 1999.

OLIVEIRA, Jardel Gomes de. NETO, Aderaldo Gonçalves do Nascimento. DANTAS, José Marilson. Avaliação do ensino no curso de ciências contábeis: o olhar dos discentes da universidade federal da Paraíba. XI ENCONTRO DE INICIAÇÃO À DOCÊNCIA: UFPB PRG. Anais... João Pessoa: 2008.

PELEIAS, Ivam Ricardo; SILVA, Glauco Peres da; SEGRETI, João Bosco; CHIROTTO, Amanda Russo. Evolução do ensino da contabilidade no Brasil: uma análise histórica. Revista de Contabilidade e Finanças da USP, ed. 30 anos de doutorado, p. 19-32, Jun. 2007.

RIVAS, Noeli Prestes Padilha; CONTE, Karina de Melo; AGUILAR, Gabriella Meier. Novos espaços formativos na universidade: desafios e perspectivas Para a docência superior. IX CONGRESSO ESTADUAL PAULISTA SOBRE FORMAÇÃO DE EDUCADORES UNESP. Anais... São Paulo: 2007.

SCHMIDT, Paulo. História do pensamento contábil. Porto Alegre: Bookman, 2000.

SACHUK, Maria Iolanda; SHINZAKI, Keiko. Projetos pedagógicos dos cursos de Ciências Contábeis: depositários ou criadores de conhecimento? Revista de Contab. Vista \& Rev., v. 18, n. 4, p. 105-128, out./ dez. 2007.

SILVA, Antonio Carlos Ribeiro da. Ensino da contabilidade: alguns aspectos sugestivos e críticos da graduação após resultado do exame nacional de desempenho dos estudantes (ENADE) 2006. Revista Universo Contábil, v. 4, n. 3, p. 82-94, jul./set. 2008.

SILVA, Decíria Fernandes. Formação do egresso do curso de ciências contábeis: estudo de caso de duas IES da cidade de Goiânia. $6^{\mathrm{a}}$ MOSTRA DE PRODUÇÃO CIENTÍFICA DA PÓS-GRADUAÇÃO LATO SENSU DA PUC GOIÁS. PUC. Anais... Goiás, 2011.

VESCO, Delci Grapeggia Dal. O Ensino de contabilidade no Brasil. Revista CAP Accounting and Management, v. 1, n. 1, 2006. 